\title{
2.2 Credibility
}

\section{Mark Kebbell}

See also chapter 2.5 Eyewitness testimony, chapter 2.9 Investigative interviewing, chapter 2.23 Statement validity analysis, chapter 2.18 Polygraphy, chapter 4.3 Interpersonal deception detection, chapter 2.25 Vulnerable adults' capacity.

\section{Definition}

Credibility can be broadly defined as a judgement concerning the quality and veracity of evidence. In a forensic context, credibility judgements are often of critical importance because of the frequency of disputed accounts. For example, a woman might say she was raped by a man who in turn says she is lying, or a shopkeeper may accuse a person of robbery and the claim made that it was a case of mistaken identity. In both these situations a credibility assessment needs to take into account whether an individual is being deliberately deceptive or the individual is indeed mistaken about some of the evidence he or she provides. Of course, it is possible for an individual to be both deceptive and mistaken. For example, a rape victim may try to give an honest account of the rape, which is generally accurate but has some errors, but then lie by saying she was abducted by the offender when she went with the offender voluntarily.

\section{Origins and further developments}

Where there is disagreement about what has happened, considerable attention has been paid to ways of determining how much credibility is warranted, most especially in detecting deception (see Vrij 2006 for a review). Some techniques that have been proposed include the polygraph, Statement Validity Analysis and Scientific Content Analysis. These techniques are dealt with elsewhere so will not be covered here, except to say that deception is more difficult to detect than might be expected, and people tend to overestimate their abilities to do so 
(again, see Vrij 2006 for a review).The focus here will be on assessing the credibility of accounts from a witness which involve judgements of the accuracy of the witness's memory.

There is a common belief that witnesses'confidence in their accuracy to infer their likely accuracy is reliable (e.g. Lindsay, Wells and Rumpel 1981). However, whilst witness confidence can be indicative of accuracy (e.g. Kebbell, Wagstaff and Covey 1996), particularly when witnesses are asked about items or events for which they have a strong memory, there are many situations where confidence is not a good indicator of accuracy. For instance, Luus and Wells (1994) found that feedback confirming or disconfirming witnesses' identifications had a marked impact on those witnesses' subsequent confidence in their inaccurate identifications. Hence, a more thorough assessment of credibility is likely to be necessary than simply asking the witness how sure they are of particular details.

Importantly, memory is not like a video camera. A video camera captures all of the events that are viewed in the direction in which it is pointed, records them and can replay them, but human memory cannot do this. Moreover, memory is an active, creative process that can be inaccurate for a variety of reasons. For material to be remembered it goes through three main stages: it is encoded into memory, stored there and finally retrieved. Problems can occur at each of these stages. Therefore, to determine witness accuracy a thorough assessment of the encoding, storage and retrieval processes, as well as the witness's capabilities more generally, is necessary.

\section{Method}

To evaluate the accuracy of an individual's account the expert should first gather as much information as possible concerning how the witness came to remember the event(s) in question. Where possible, the expert should seek documentary evidence to construct a time-line of events, and scrutinize issues that may have influenced memory production. This process might start with attempting to determine how the witness came to perceive the event, and whether they tried to deliberately encode what they were witnessing. Due to our limited capacity for attention, we can neither attend to, nor take in, all the information in our environment at any particular time and, as a consequence, information that is not attended to is unlikely to be remembered.

As people do not encode everything they observe, storage of memories often contains gaps. To make sense of these gaps, people may 'fill them in' to 
fit with previous attitudes, beliefs and expectations about a particular event or person. External sources may also be incorporated into memory. For example, if someone is e told, incorrectly, that a person they met had a moustache, this information may be incorporated into memory and may come to be believed. In a similar fashion other people's accounts of an event may be incorporated into that of another witness. Therefore, it is important for the expert to find out what other sources of information the individual might have been exposed to, and this may be problematic as witnesses often are not aware of factors that have influenced their memories.

Successful retrieval from memory depends not only on adequate encoding and storage but on other factors as well. Retrieval strategies, such as the way a witness is interviewed, can have a profound impact. Research indicates that suggestive questioning, in particular, can have a negative impact on the accuracy of witness accounts (Loftus 1975). Therefore the expert should endeavour to find out how the memories were elicited. Finally, characteristics of the witness, for instance, if they have an intellectual disability or were intoxicated, are all likely to interact with factors at encoding, storage and retrieval to determine memory accuracy.

The fact that there may be problems with memory means that individuals may also not be able to give accurate accounts of how they came to remember events, requiring that the expert collects as much collateral information as is available. For example, the psychologist might request CCTV which gives an indication of the level of intoxication of the witness at the time of a crime, interview tapes to show how suggestive (or otherwise) the interview was, media reports that may have influenced the individual's memory over time, physical forensic or medical evidence, the opposing side's accounts, school records, and other independent eyewitness accounts.

\section{Evaluation}

Evaluation is problematic because of the many different factors, including potential unknowns, that are likely to have an influence on the credibility of an account, such as difficulties in relying on the individual for information concerning how they came to remember the incident or person.

As a starting point, some of the critical factors that need to be considered are given in the Turnbull Ruling ( $R$ v. Turnbull and others 1977) and can be remembered with the mnemonic 'ADVOCATE' standing for Amount of time under observation, Distance from the eyewitness to the person/incident, 
Visibility, Obstructions, Known or seen before, Any reason to remember, Time lapse since the event, Errors or material inconsistencies. In addition, factors such as stress and violence are likely to have a profound impact on memory accuracy and need to be borne in mind (see Christianson 1992).

Factors associated with the witness are also relevant; for example, research has identified a number of characteristics of the witness that may affect the accuracy of eyewitness accounts (see Kebbell and Wagstaff 1999). In general children, and indeed older adults, are poorer than adults from the general population in aspects of encoding, storage and retrieval, but their ability to give accounts is most influenced by how they are interviewed, as is discussed later. Similarly, people with intellectual disabilities also vary considerably in their ability to report details, and are sensitive to the way in which they are questioned; and while the influence of mental illness on witnessing abilities is poorly understood, it appears to have a negative impact. Alcohol and drugs can also have a negative impact as can head injuries.

Particularly important to judgements of credibility is the way in which accounts are elicited. Interviewing strategies such has hypnosis have a welldocumented history of eliciting distorted accounts (for a review see Kebbell and Wagstaff 1999, and see also chapter 6.7, this volume). More appropriate interview strategies include the Cognitive Interview (Fisher and Geiselman 1992; see also chapter 2.9, this volume) which relies on mental reinstatement of context and open questioning. Witnesses tend to give the most accurate answers to open questions but as questions become more and more specific and closed, so accuracy rates fall. In particular, leading questions, such as 'Was his shirt red?', can decrease accuracy levels. Ideally, interviewers should have adopted a phased approach with more open questioning at the start of the interview. In these cases the initial content of the 'open' account is more accurate, potentially, than subsequent details elicited in a more closed fashion, and this is worth considering (Milne and Bull 1999).

Experts should carefully consider the above points before drawing general conclusions. There is a great deal of difficulty of generalizing from empirical evidence to particular cases, partly because of the lack of ecological validity inherent in many eyewitness studies, and partly because it is difficult to predict how multiple factors that might be both positive and negative for memory may interact. An example serves to illustrate these points. A credibility assessment was requested concerning a man who witnessed a shooting murder. He had a reason to be looking at the people involved because they were arguing loudly and it was late. The people, including the shooter, were poorly illuminated by street lights. The witness was in his sixties with reasonable 
eyesight and had been drinking. He gave more than ten accounts of the shooting, which gradually changed over time, and he became more confident in his accounts. It was possible to accurately determine the distance over which the witness saw the shooting and the level of illumination - both of which were quite different from what the witness reported. In this case, some factors were likely to have a positive influence on his accuracy, such as the fact that the witness paid attention to the shooting and had reasonable eyesight. However, other factors were likely to be less positive, for example, that he had been drinking and that his account, and his confidence, had changed substantially over time, the lack of light and his distance from the shooting. These various factors were taken into consideration to give an assessment of what parts of his account were more or less reliable.

\section{Applications}

Formal credibility assessments, if properly conducted, may help clarify the reliance that can be put on a witness's evidence. Recent research indicates why this might be important. Ask and Granhag (2007) found that witness evidence that was consistent with investigators' beliefs about what had happened was perceived by the investigators to be more credible than witness evidence that was not consistent. Credibility assessment can potentially reduce this effect.

\section{Conclusion}

To conclude, evaluating credibility is a complex and often ambiguous task focusing on the likely accuracy and deceptiveness of an individual. Here the focus has been on credibility in terms of memory capabilities, which is likely to be able to give a general indication of the accuracy of an account and potentially prevent over-, and under-, reliance on a witness's account.

\section{FURTHER READING}

For a general review of factors that influence eyewitness evidence the reader might wish to look at Kebbell and Wagstaff (1999). For a review of how an expert might wish to evaluate a case of delayed abuse the reader may wish to refer to L. J. Alison, M. R. Kebbell and P. Lewis (2006) 
Psychological and legal problems in criminal cases of delayed reports of sexual abuse. Psychology, Public Policy, and Law, 12: 419-41.

\section{REFERENCES}

Ask, K. and Granhag, P. A. (2007) Motivational bias in criminal investigators' judgments of witness reliability. Applied Social Psychology, 37: 561-91.

Christianson, S.A. (1992) Emotional stress and eyewitness memory: a critical review. Psychological Bulletin, 112: 284-309.

Fisher, R.P. and Geiselman, R.E. (1992) Memory-enhancing Techniques for Investigative Interviewing: The Cognitive Interview. Springfield, IL: Thomas.

Kebbell, M.R. and Wagstaff, G. F. (1999) Face Value? Factors that Influence Eyewitness Accuracy. London: Home Office. Available online: www.homeoffice.gov.uk/rds/prgpdfs/ fprs102.pdf.

Kebbell, M. R., Wagstaff, G. F. and Covey, J. A. (1996) The influence of item difficulty on the relationship between eyewitness confidence and accuracy. British Journal of Psychology, 87: 653-62.

Lindsay, R. C. L., Wells, G. L. and Rumpel, C. (1981) Can people detect eyewitness identification accuracy within and across situations? Journal of Applied Psychology, 66: 79-89.

Loftus, E. F. (1975) Leading questions and eyewitness report. Cognitive Psychology, 7: 560-72.

Luus, E. C. A. and Wells, G. L. (1994) The malleability of eyewitness confidence: co-witness and perseverance effects. Journal of Applied Psychology, 79: 714-23.

Milne, R. and Bull, R. (1999) Investigative Interviewing: Psychology and Practice. Chichester: Wiley.

R. v Turnbull and others (1977) QB 224; (1976) 3 AVE R 549 at pp. 549-50.

Vrij, A. (2006) Detecting deception. In M.R. Kebbell and G.M. Davies (eds.), Practical Psychology for Forensic Investigations and Prosecutions, pp. 89-102. Chichester: Wiley. 